\title{
Outcomes after thoracoabdominal aortic aneurysm repair using hypothermic circulatory arrest
}

\author{
Nicholas T. Kouchoukos, MD, ${ }^{\mathrm{a}}$ Alexander Kulik, MD, MPH, ${ }^{\mathrm{b}}$ and Catherine F. Castner, $\mathrm{RN}^{\mathrm{a}}$
}

Objective: To evaluate our experience with thoracoabdominal aortic aneurysm repair using cardiopulmonary bypass and hypothermic circulatory arrest.

Methods: A total of 243 patients underwent thoracoabdominal aortic aneurysm repair with full cardiopulmonary bypass and hypothermic circulatory arrest. The degree of repair was Crawford extent I in 63 (26\%), Crawford extent II in 97 (40\%), and Crawford extent III in 83 patients (34\%). Degenerative aneurysms were the most frequent indication for surgery, and 18 patients $(7.4 \%)$ required emergency surgery.

Results: The mean duration of cardiopulmonary bypass and hypothermic circulatory arrest was $160 \pm 44$ and $31 \pm 12$ minutes, respectively. Stroke occurred in 9 patients $(3.7 \%)$ and spinal cord ischemic injury in 13 patients $(5.3 \%$; 9 with paraplegia and 4 with paraparesis). Temporary dialysis for new-onset renal failure was required in $3.6 \%$ of hospital survivors. The 30-day mortality rate was $7.8 \%$ (13 patients). It was $33.3 \%$ after emergency surgery and $5.6 \%$ after elective surgery $(P=.001)$. Spinal cord ischemic injury occurred more frequently after emergency than after elective surgery $(16.7 \%$ vs $3.9 \% ; P=.04)$. The overall 5 -year survival was $55 \%$ and was significantly better for patients with nondegenerative aortic disease.

Conclusions: Cardiopulmonary bypass with hypothermic circulatory arrest can be safely used for thoracoabdominal aortic aneurysm repair, providing excellent protection against end-organ injury. The early and late mortality rates did not exceed those reported for other open techniques or for endovascular repair, with particularly favorable outcomes among patients undergoing elective repair. (J Thorac Cardiovasc Surg 2013;145:S139-41)

Several approaches exist for the open surgical repair of thoracoabdominal aortic aneurysms (TAAAs), including the clamp-and-sew technique and the use of distal perfusion either with partial (left heart) or total cardiopulmonary bypass (CPB). To prevent visceral, renal, and spinal cord ischemic injury (SCII), these strategies can be supplemented with epidural cooling, cerebrospinal fluid drainage, renal and visceral perfusion, and the monitoring of motor and somatosensory evoked potentials. ${ }^{1-5}$

$\mathrm{CPB}$ with intervals of hypothermic circulatory arrest is a widely used technique for the protection of the central nervous system during complex cardiac and proximal thoracic aortic procedures. It has been used less frequently for repair of TAAA. Its advantages compared with other techniques in this setting include minimal aortic dissection and the elimination of the need for proximal and sequential aortic clamping. It also affords access to the distal aortic arch,

\footnotetext{
From the Division of Cardiovascular and Thoracic Surgery, ${ }^{\mathrm{a}}$ Missouri Baptist Medical Center, St Louis, Mo; and Division of Cardiothoracic Surgery, ${ }^{\mathrm{b}}$ Lynn Heart Institute, Boca Raton Regional Hospital, Boca Raton, Fla.

Disclosures: Drs Kouchoukos, Kulik, and Castner have nothing to disclose with regard to commercial support.

Presented at The American Association for Thoracic Surgery Aortic Surgery Symposium 2012, April 26-27, 2012, New York, NY.

Received for publication May 8, 2012; revisions received Aug 15, 2012; accepted for publication Nov 28, 2012; available ahead of print Dec 20, 2012.

Address for reprints: Nicholas T. Kouchoukos, MD, Division of Cardiovascular and Thoracic Surgery, Missouri Baptist Medical Center, 3009 N Ballas Rd, Suite 360C, St Louis, MO 63131 (E-mail: ntkouch@aol.com).

$0022-5223 / \$ 36.00$

Copyright (C) 2013 by The American Association for Thoracic Surgery

http://dx.doi.org/10.1016/j.jtcvs.2012.11.077
}

a bloodless field, the return of shed blood into the perfusion circuit, and a reduced potential for the atheromatous embolization that can result from aortic clamping. Hypothermic circulatory arrest provides protection of the central nervous system, heart, and abdominal organs without the need for monitoring of evoked potentials or separate perfusion of the renal and visceral arteries. ${ }^{6,7}$

\section{METHODS \\ Patient Characteristics}

From January 1986 to March of 2012, 243 patients underwent TAAA repair with $\mathrm{CPB}$ and hypothermic circulatory arrest. No other operative technique was used during the study period. The mean age at surgery was $64 \pm 14$ years (range, 15-86 years), and 125 patients were female $(51 \%)$.

Degenerative aneurysms were present in 177 patients $(73 \%)$. A total of 60 patients $(25 \%)$ had chronic type B dissections with aneurysm, and 3 patients $(1.2 \%)$ presented with complicated acute type B dissections. Also, 18 patients $(7.4 \%)$ underwent emergent operation for rupture or acute dissection. The extent of aortic disease requiring replacement is listed in Table 1. The institutional review board of the Missouri Baptist Medical Center reviewed the study and exempted it from board approval.

\section{Operative Technique}

Our operative technique has been previously described in detail. ${ }^{6,7}$ With increasing experience, modifications were introduced. Since September 2004, cerebrospinal fluid drainage has been used, when technically feasible. A standard posterolateral thoracoabdominal incision is made through the fifth or sixth intercostal space. Simultaneously, the left femoral artery and vein are isolated for cannulation. Because femoral artery perfusion might lead to retrograde embolization of thrombus or 


\section{Abbreviations and Acronyms \\ $\mathrm{CPB}=$ cardiopulmonary bypass \\ TAAA $=$ thoracoabdominal aortic aneurysm \\ SCII $=$ spinal cord ischemic injury}

TABLE 1. Extent of aortic repair

\begin{tabular}{lc}
\hline Extent of repair (Crawford) & Patients (n) \\
\hline Type I & $63(26)$ \\
Type II & $97(40)$ \\
Type III & $83(34)$ \\
Total & $243(100)$ \\
\hline
\end{tabular}

Data in parentheses are percentages.

\section{Morbidity}

Stroke occurred in 9 patients $(3.7 \%)$. SCII occurred in 13 atheroma into the cerebral circulation, in 1997, we modified our surgical technique and currently insert a second arterial perfusion cannula directly into the descending thoracic aorta at a noncalcified, thrombus-free site identified by epiaortic ultrasound scanning.

Cooling is initiated after establishing full CPB. The left heart is vented, and when the nasopharyngeal temperature reaches $22^{\circ} \mathrm{C}$ or less, and electroencephalographic silence is achieved, circulatory arrest is established. Cardioplegia is not administered, and the somatosensory and motor evoked potentials are not monitored. The diseased segment of the aorta is incised and the site for proximal anastomosis of an aortic graft identified. The aorta is completely transected at this level, and a polyester graft containing a $10-\mathrm{mm}$ side arm is sutured end-to-end to the divided aorta. Once this suture line is completed, cold blood $\left(10^{\circ}-12^{\circ} \mathrm{C}\right)$ from the pump-oxygenator is infused retrogradely into the venous cannula to assist in the evacuation of air and debris from the upper circulation and from the graft. Blood is infused at a rate of 600 to $700 \mathrm{~mL} / \mathrm{min}$, keeping the central venous pressure at or less than 20 $\mathrm{mm} \mathrm{Hg}$. The side arm of the graft is attached to the proximal arterial line from the pump-oxygenator. After evacuation of air, a clamp is placed on the graft just distal to the side arm, and flow to the upper body is established.

Before 2003, the visceral and renal arteries were attached to the aortic graft as a Carrel patch, using a full-thickness cuff of native aortic tissue. Subsequently, the visceral and renal arteries were separately reimplanted using a woven polyester, 4-branch aortic graft (MAQUET Cardiovascular LLC, Wayne, NJ). ${ }^{8,9}$ With this technique, the arteries are detached from the aorta with a small cuff of aortic tissue. If the origin of the artery is severely stenotic, the vessel is transected beyond the stenosis. The body of the aortic branch graft is positioned such that the 3 adjacent branches lie opposite the origins of the right renal, superior mesenteric, and celiac arteries. After completion of the anastomosis to the distal aorta, flow is restored to the lower body using the femoral artery cannula, and the branches are sequentially attached to these 3 vessels. The left renal artery is sewn either to the fourth (perpendicular) branch or to a separate 6- to 10-mm interposition graft. After each anastomosis is completed, the distal clamp is repositioned more proximally to enable perfusion of each reimplanted artery. Rewarming is initiated at this point, and patent lower intercostal or upper lumbar arteries, if present, are attached to the aortic graft with a patch of aorta. The final anastomosis of the aortic graft to the proximal aortic graft is completed. After evacuation of air, a full antegrade flow is established from the proximal arterial line. CPB is discontinued when the nasopharyngeal temperature reaches $37^{\circ} \mathrm{C}$, and the core (bladder) temperature reaches $35.5^{\circ} \mathrm{C}$. The mean duration of $\mathrm{CPB}$ and circulatory arrest was $160 \pm 44$ and $31 \pm 12$ minutes, respectively.

\section{RESULTS}

\section{Early Mortality}

The 30-day mortality for the entire group was $7.8 \%$ (19 patients). It was $33.3 \%$ after emergency surgery (6 patients) and 5.6\% after elective surgery (13 patients; Table 2). patients $(5.3 \%), 9$ with paraplegia and 4 with paraparesis. It occurred more frequently after emergency than after elective surgery ( 3 patients $[16.7 \%$ ] vs 10 patients [3.9\%], respectively; $P=.04$; Table 2 ). The rate of SCII among the 75 patients with and 168 patients without perioperative cerebrospinal fluid drainage was $5.4 \%$ and $5.3 \%$, respectively. Temporary renal dialysis was required in 8 of the 224 hospital survivors (3.6\%). In a previous report analyzing the outcomes in 218 patients who underwent surgery until December 2008, the significant independent predictors of the composite outcome (30-day mortality, SCII, stroke, and the need for dialysis) were preoperative creatinine level $(P=.004)$, emergency surgery $(P=.008)$, older age $(P=.006)$, the presence of coronary artery disease $(P=.03)$, and increasing duration of CPB $(P=.05){ }^{7}$

\section{DISCUSSION}

In use for more than 50 years, hypothermic CPB with intervals of circulatory arrest is a safe and effective method for protecting the central nervous system during complex cardiac surgery. Applying this technique during TAAA repair provides a bloodless field and access to the aortic arch. It eliminates the need for proximal and sequential clamping and extensive mobilization of the aorta. Most of the shed blood is returned to the perfusion circuit. Adjunctive measures, such as separate perfusion of the visceral and renal arteries, epidural cooling, and monitoring of evoked

TABLE 2. Morbidity and mortality $(n=243)$

\begin{tabular}{lc}
\hline \multicolumn{1}{c}{ Variable } & Value \\
\hline 30-d Mortality & $13(7.8)$ \\
Stroke & $9(3.7)$ \\
SCII & $13(5.3)$ \\
$\quad$ Paraplegia & 9 \\
$\quad$ Paraparesis & 4 \\
Temporary dialysis (hospital survivors) & $9(3.7)$ \\
Elective surgery* $(\%)$ & \\
$\quad$ Mortality & 5.6 \\
$\quad$ SCII & 3.9 \\
Emergent surgery $\dagger(\%)$ & \\
$\quad$ Mortality & 33.3 \\
$\quad$ SCII & 16.7 \\
\hline Data presented as n $(\%)$, unless otherwise noted. SCII, Spinal cord ischemic injury. \\
$* P=.001 . \dagger P=.04$.
\end{tabular}


potentials, are not necessary. Hypothermia increases ischemic tolerance and allows unhurried aortic reconstruction.

\section{CONCLUSIONS}

Our results indicate that, when applied on a routine basis, the repair of TAAAs using hypothermic CPB and circulatory arrest is a safe technique. The results compared favorably with those using alternative open and currently used endovascular and hybrid debranching surgical techniques. ${ }^{7}$

\section{References}

1. Conrad MF, Crawford RS, Davison JK, Cambria RP. Thoracoabdominal aneurysm repair: a 20-year perspective. Ann Thorac Surg. 2007;83:S856-61; discussion S890-2.

2. Acher CW, Wynn MM, Mell MW, Tefera G, Hoch JR. A quantitative assessment of the impact of intercostal artery reimplantation on paralysis risk in thoracoabdominal aortic aneurysm repair. Ann Surg. 2008;248:529-40.
3. Coselli JS, Bozinovski J, LeMaire SA. Open surgical repair of 2286 thoracoabdominal aortic aneurysms. Ann Thorac Surg. 2007;83:S862-4; discussion S890-2.

4. Etz CD, Halstead JC, Spielvogel D, Shahani R, Lazala R, Homann TM, et al Thoracic and thoracoabdominal aneurysm repair: is reimplantation of spinal cord arteries a waste of time? Ann Thorac Surg. 2006;82:1670-7.

5. Safi HJ, Miller CC III, Huynh TT, Estrera AL, Porat EE, Winnerkvist AN, et al Distal aortic perfusion and cerebrospinal fluid drainage for thoracoabdominal and descending thoracic aortic repair: ten years of organ protection. Ann Surg. 2003;238:372-80; discussion 380-1.

6. Kouchoukos NT, Masetti P, Rokkas CK, Murphy SF, Blackstone EH. Safety and efficacy of hypothermic cardiopulmonary bypass and circulatory arrest for operations on the descending thoracic and thoracoabdominal aorta. Ann Thorac Surg. 2001;72:699-707; discussion 707-8.

7. Kulik A, Castner CF, Kouchoukos NT. Outcomes after thoracoabdominal aortic aneurysm repair with hypothermic circulatory arrest. J Thorac Cardiovasc Surg. 2011;141:953-60.

8. Kouchoukos NT, Masetti P, Castner CF. Use of presewn multiple branched graft in thoracoabdominal aortic aneurysm repair. J Am Coll Surg. 2005;201:646-9.

9. Kulik A, Castner CF, Kouchoukos NT. Patency and durability of presewn multiple branched graft for thoracoabdominal aortic aneurysm repair. J Vasc Surg. 2010;51: 1367-72. 